مقاله يزوهشى

مجله دانشعاه علوم :ز شكى رفسنجان

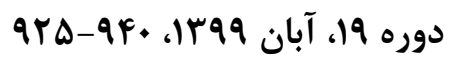

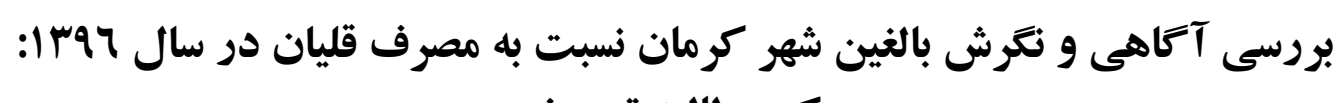

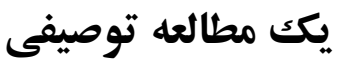

مينا دانايى '، محسن مؤمنى ' مون

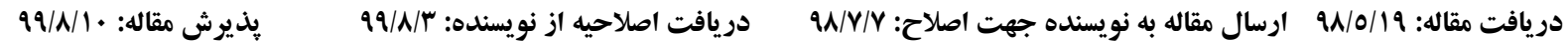

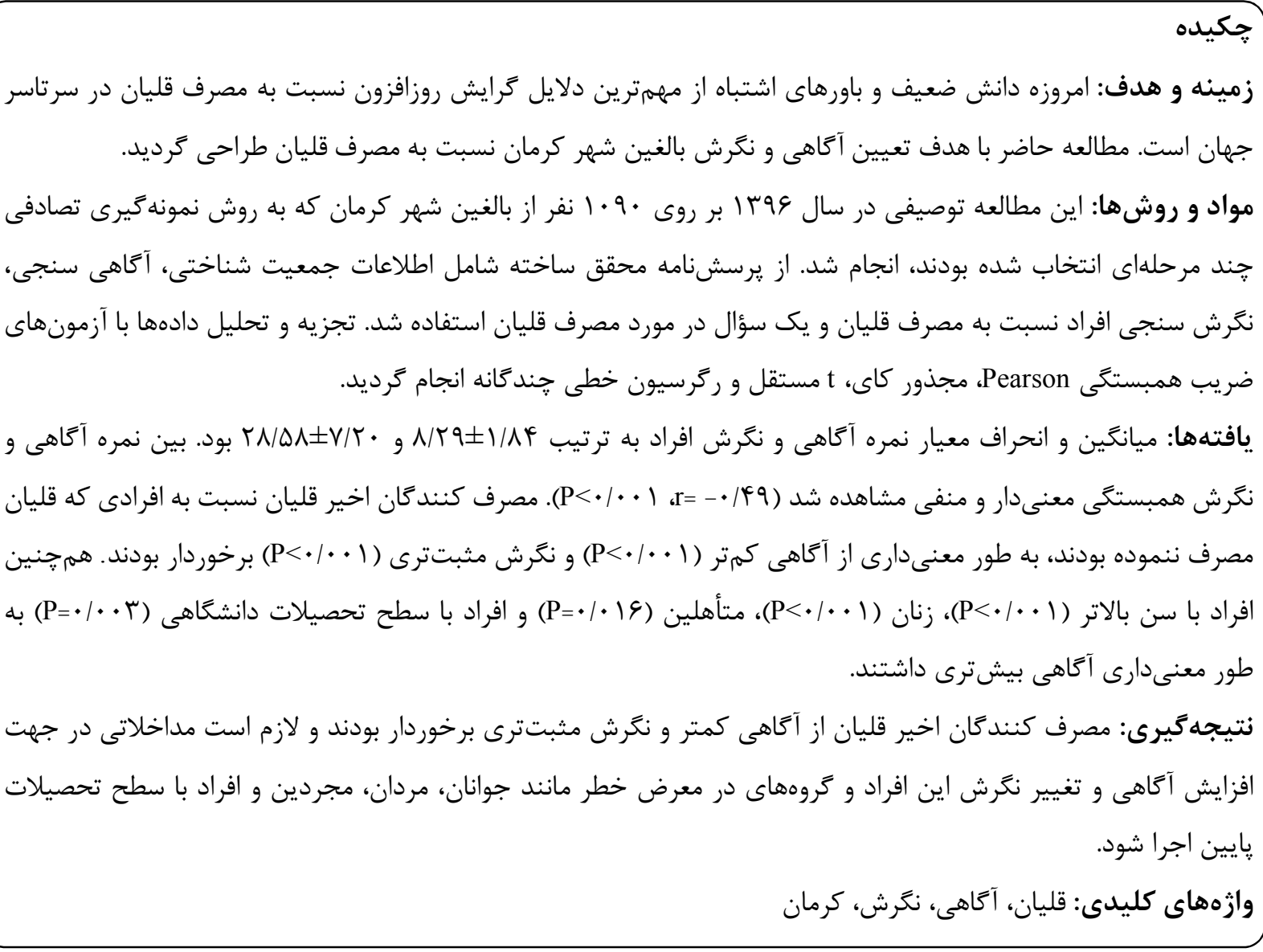

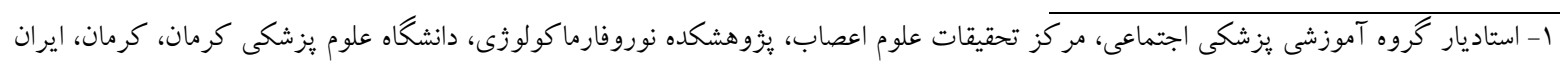

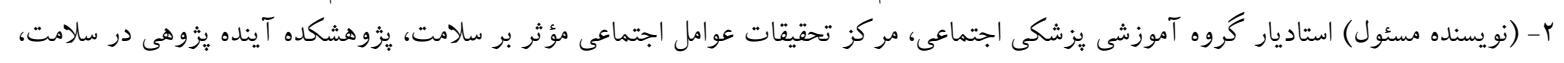

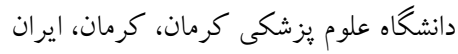

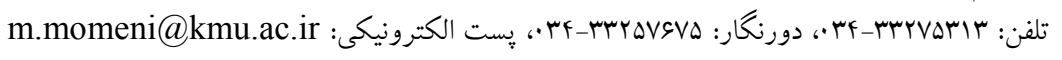


سريعى داشته است [ [1-9]. بر اساس نتايج يك مطالعه ملى

مقدمه

در ايران، شيوع روزانه مصرف قليان در مردان و زنان به ترتيب T/V و T/T درصد Fزارش شد و مشخص گرديد كه مناطق جنوب و جنوب شرق ايران داراى بالاترين شيوع مصرف قليان مىباشند [ 1 1 ]. نتايج مطالعهاى در سال هوس ا در شهر كرمان نشان داد كه شيوع روزانه، يك ماه اخير و در طول عمر مصرف

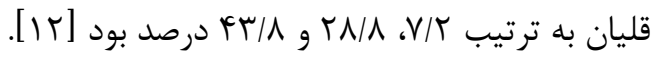
امروزه مصرف قليان به يك يديده اجتماعى به ويزه در ميان جوانان تبديل شده است و افراد آن را به عنوان يك تفريح و سرگرمى و وسيلهاى مناسب براى يركردن اوقات فراغت و دور همنشينى و جمع شدن دوستان دور هم مىشناسند [1 ا]]. همجنين يذيرش اجتماعى مصرف قليان در مقايسه با سيكار كشيدن به خصوص در ميان زنان در ساليان اخير افزايش يافته است. حتى در منطقه خاورميانه بسيارى قليان كشيدن را به

عنوان قسمتى از هويت فرهنكى خود يذيرفتهاند [4 ا [ ]. يكى از دلايل اصلى گرايش روزافزون به مصرف قليان، دانش ضعيف و باورهاى غلط جوامع نسبت به خطرات بالقوه تهديد كننده سلامتى اين يديده اجتماعى است. نتايج يك مطالعه در ايران نشان داد كه تنها \&1 درصد از مصرف كنندكان قليان از سواد سلامت كافى برخوردار مىباشند [ [1] ]. نتايج برخى مطالعات در اين زمينه نشان مىدهد كه اكثر افراد مصرف كننده قليان، مضرات آن را كمتر از سيكار كشيدن مىدانند و حتى برخى قليان را يك روش سالم براى استفاده از تنباكو قلمداد مىنمايند و اعتقاد دارند كه مواد مضر موجود در تنباكوى قليان هنكام عبور از آب تصفيه مىشوند
در ساليان اخير الكوى جهانى مصرف دخانيات تغيير نموده است، به طورى كه علىرغم كاهش شيوع مصرف سيكار اما ساير انواع مصرف دخانيات به ويزه مصرف قليان در بسيارى از مناطق دنيا افزايش يافته است و امروزه مصرف قليان به يك إييدمى جهانى و تهديد جدى براى سلامت عمومى در سرتاسر دنيا تبديل شده است [ع-1]]. در اواخر قرن نوزدهم و اوايل قرن بيستم ميلادى، قليان كشيدن با تنباكوى معمولى در ميان مردان مسن منطقه خاورميانه رواج داشت [ه] ولى از اوايل دهه •199 مصرف قليان با تنباكوى طعمدار (ميوهاى) به سرعت در ميان جوانان اين منطقه افزايش يافت [ع] به نحوى كه امروزه كشيدن قليان به محبوبترين روش استفاده از تنباكو در ميان جوانان خاورميانه تبديل شده است [1]. علىرغم اثرات زيانآور متعدد مصرف قليان بر سلامتى، مطالعات اخير دلالت بر افزايش سريع شيوع مصرف قليان به ويزه در ميان نوجوانان و جوانان سرتاسر دنيا دارد و در حال حاضر منطقه مديترانه شرقى (شامل كشورهاى خاورميانه و شمال آفريقا) داراى بيشترين شيوع مصرف قليان در جهان است [V]. نتايج مطالعات نشان داد كه بالاترين شيوع مصرف

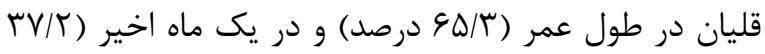
درصد) مربوط به جوانان لبنانى بود. همرجنين بالاترين شيوع مصرف روزانه قليان (أ/ • درصد) مربوط به جوانان مصرى و به صورت منظه يا كاه أهى ( آ/ | درصد) مربوط به دانشجويان ايرانى بود [N]. در ايران نيز شيوع مصرف قليان به خصوص در ميان نوجوانان، جوانان و زنان در ساليان اخير رشد 
دمانس و عدم صحت عقل كامل كه منجر به ناتوانايى فرد در ياسخ دادن به سؤالات مى گرديد، اين افراد از مطالعه كنار كذاشته مىشدند. اين تحقيق توسط كميته اخلاق دانشگاه IR.KMU.REC.1394.262 علوم يزشكى كرمان با كد اخلاق

$$
\text { مورد تأييد قرار ترفت. }
$$

با توجه به مطالعات بيشين و با در نظر ترفتن انحر اف معيار

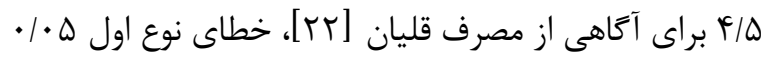
و خطاى قابل قبول در برآورد ميانگين مورد نظر س/، •، و با استفاده از فرمول تعيين حجم نمونه براى برآورد يك ميانگين

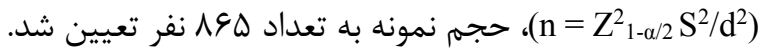
با در نظر گرفتن ميزان عدم ياسخدهى (Withdrawal rate)

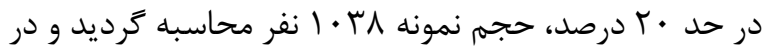
نهايت • • 11 نفر وارد مطالعه شدند. جهت نمونهگيرى، از روش نمونه گيرى تصادفى جند مرحلهاى استفاده گرديد. در اين روش ابتدا شهر كرمان بر اساس تقسيمبندى شهردارى به جهار منطقه تقسيم شد و سيس به صورت تصادفى از هر منطقه تعدادى خيابان و از هر خيابان تعدادى كوجه به شكل تصادفى انتخاب گرديد. در نهايت، در هر كوجه تعدادى خانه و از هر خانه يك نفر به طور تصادفى وارد مطالعه شد. انتخاب تصادفى در هر مرحله با استفاده از جدول اعداد تصادفى انجام گرفت. ابزار جمعآورى دادهها، يرسشنامه محقق ساختهاى بود كه به روش خود ايفا توسط شركت كنندگان در مطالعه تكميل مى گرديد و در صورت داشتن مشكل در درك برخى عبارات يرسشنامه، توضيحات لازم توسط يرسش گران دوره ديده داده

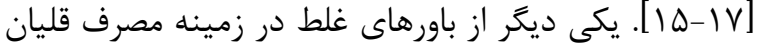
عدم ايجاد وابستخى و اعتيادآورى اين روش مصرف تنباكو در ميان مصرف كنندگان آن است. همرجنين از ساير باورهاى غلط در اين زمينه مىتوان به اين موضوع اشاره نمود كه بسيارى از مصرف كنندگان قليان، آن را وسيلهاى جهت كاهش اضطراب و استرس و رفع خستخى مىدانند [19-11]]. از ساير علل افزايش شيوع مصرف قليان به خصوص در ميان جوانان مىتوان به محبوبيت طعم و بوى تنباكوى طعم دار، هزينه نسبتاً پايين، حس كنجكاوى، فشار همسالان، عدم وجود نظارت مناسب بر اجراى قوانين محدوديت مصرف دخانيات، تبليغات رسانهاى جمعى و گسترش كافهها و رستورانهاى عرضه كننده قليان اشاره كرد [إr-•r]. لذا با توجه به شيوع روزافزون مصرف قليان در جامعه ايرانى و عنايت به اين موضوع كه دانش ضعيف و باورهاى غلط از مهرمترين دلايل گرايش مردم به مصرف قليان است [זI]]، مطالعه حاضر با هدف تعيين آكاهى و نكرش بالغين كرمانى نسبت به مصرف قليان طراحى گرديد تا با استفاده از نتايج آن بتوان راهكارهاى مناسبى جهت كاهش شيوع اين معضل

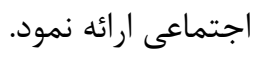

\section{مواد و روشها - - ماد}

اين مطالعه توصيفى بر يايه جمعيت در سال عوبا در شهر كرمان انجام شد. معيارهاى ورود به مطالعه داشتن سن 11 سال يا بالاتر و سكونت در شهر كرمان حداقل در ه سال كذشته و توانايى خواندن و نوشتن بود. همرجنين در صورت عدم تمايل افراد به شركت در مطالعه و داشتن مشكلاتى مانند 
مصرف قليان در يك ماه گذشته (مصرف اخير) نيز مورد سؤال

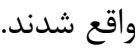

جهت طراحى :رسشنامه مورد نظر، محققين در ابتدا با استفاده از منابع معتبر و مرتبط اقدام به استخراج عبارات در هر حيطه نمودند. سيس با استفاده از مصاحبه با افراد صاحب نظر در زمينه مصرف قليان و دخانيات و انجام بحثهاى كروهى متمركز، تك تك عبارات مورد بحث قرار كرفت و به اين صورت روايى يرسشنامه تأييد گرديد. همجنين جهت سنجش روايى زرسشنامه با استفاده از روى كرد كمى از شاخص روايى محتوا (Content validity index; CVI) استفاده شد [rr]]. در اين روش در مرحله اول يس از تهيه يیشنويس يرسش نامه، يك تيم مجرب متشكل از پينج نفر كه در خصوص موضوع مورد نظر تجربه لازم را داشتند، تشكيل شد. در مرحله دوم نسخهاى از يرسشنامه همراه با توضيحاتى در زمينه هدف مطالعه، سؤالات و شكل زَزينهها براى تمامى افراد ارسال گرديد. در مرحله سوم افراد ميزان ارتباط هر يك از گويههاى يرسشنامه با موضوع مورد نظر را بر اساس ززينه هاى "ارتباط دارد"، "تا حدى مرتبط است"، "مرتبط است" و "بسيار مرتبط است" مشخص نمودند. در مرحله آخر، براى هر گويه CVI محاسبه گرديد. به اين صورت كه براى هر عبارت يك كسر محاسبه شد كه صورت آن تعداد افرادى بود كه براى آن عبارت گزينههاى "مرتبط است" و "بسيار مرتبط است" را انتخاب نموده بودند و مخرج كسر را كل افراد تشكيل مىدادند. اين شاخص براى حيطه آكاهى سنجى 9 / • و براى حيطه نكرش سنجى |N|1 • محاسبه گرديد.
مىشد. اين يرسشنامه شامل سه قسمت بود؛ قسمت اول را اطلاعات جمعيت شناسى شامل سن، جنسيت، وضعيت تأهل، سطح تحصيلات، وضعيت اشتغال و سطح درآمد تشكيل مى داد. قسمت دوم را • ا عبارت در زمينه آكاهى سنجى افراد نسبت به مصرف قليان تشكيل مىداد كه افراد بايستى نظر خود را در مورد صحيح بودن عبارت مورد نظر با انتخاب ززينه "بلى" و در صورت غلط بودن با گزينه "خير" مشخص مى نمودند. جهت امتيازدهى، به گزينههاى صحيح امتياز ا و به كزينههاى غلط امتياز صفر تعلق مى ياسخ صحيح عبارات ا، ب و ه، ززينه خير را شامل مىشد، در مرحله آناليز براى اين عبارات نمرهدهى معكوس انجام شد. بدين شكل مىتوانست حداقل و حداكثر مجموع نمره آكاهى سنجى براى هر نفر به ترتيب صفر تا • ا باشد و نمره بالاتر، آكاهى بيشتر افراد را نسبت به مصرف قليان نشان مىداد. قسمت سوم يرسشنامه شامل | | عبارت در زمينه نگرش سنجى افراد نسبت به مصرف قليان را در بر مى ياسخها طيف ليكرت ه زَينهاى شامل كاملاً مخالفم (نمره ()، مخالفم (نمره Y)، نظرى ندارم (نمره ؟)، موافقم (نمره ؟) و كاملاً موافقم (نمره ه) بود. با توجه به منفى بودن بار عبارات

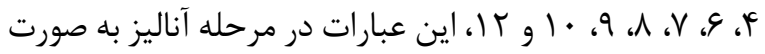
معكوس نمرهدهى شد. به اين صورت حداقل و حداكثر مجموع نمره نكرش سنجى براى هر نفر مىتوانست به ترتيب Y ا تا • باشد و نمره بالاتر نكرش مثبتتر افراد نسبت به مصرف قليان را مشخص مىنمود. همرجنين افراد مورد مطالعه در مورد 
درصد) و داراى تحصيلات دانشگاهى (ف/• ه درصد) بودند

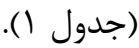

جدول ا- توزيع فراوانى ويثكىهاى جمعيت شناختى شركت

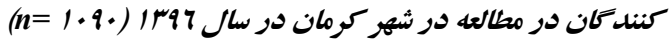

\begin{tabular}{|c|c|}
\hline 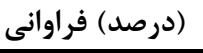 & متغير \\
\hline & جنسيت \\
\hline$\Delta F \cdot(F q / \Delta)$ & زن ان \\
\hline \multirow[t]{2}{*}{$\Delta \Delta \cdot(\Delta \cdot / \Delta)$} & 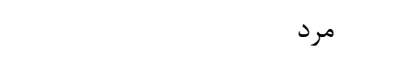 \\
\hline & وضعيت تأهل \\
\hline GKr (DV/T) & 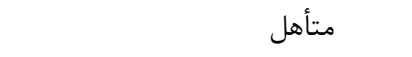 \\
\hline \multirow[t]{2}{*}{$F \& D(F T / V)$} & 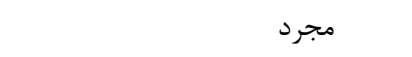 \\
\hline & سطح تحصيلات \\
\hline $\operatorname{IVG}(1 \varepsilon / Y)$ & زير دييلم \\
\hline TGT $(T \Gamma / T)$ & ديلهم \\
\hline \multirow[t]{2}{*}{$\Delta F q(\Delta \cdot \mid \Delta)$} & دانشخاهى \\
\hline & وضعيت اشتغال \\
\hline $9 \Delta \Lambda(9 \cdot 19)$ & شاغل \\
\hline TGT $(T Y / T)$ & خانهدار / بى كار \\
\hline \multirow[t]{2}{*}{$190(10 / T)$} & دانشجو \\
\hline & ميزان در آمد (ميليون ريال در ماه) \\
\hline FYI $(F F / Q)$ & كمتر از ه ه \\
\hline$F \cdots(F T / T)$ & ه تا ها \\
\hline $\mid r s(\mid r / T)$ & بالاتر از ها \\
\hline
\end{tabular}

ميانكين و انحراف معيار نمره آكاهى N/AF

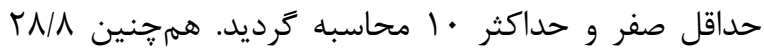
درصد از شركت كنند قليان در يك ماه اخير را گزارش نموده بودند. حدود ها درصد از كل شركت كنندكان (Yq ا نفر) و rV درصد از مصرف كنندكان اخير قليان (ه نفر) اعتقاد داشتند كه مواد مضر موجود در تنباكو به وسيله آب موجود در قليان گرفته مىشود. ميانگين و انحراف معيار نمره آكاهى به ترتيب در افراد با سابقه مصرف اخير قليان و افراد بدون سابقه مصرف اخير قليان سب/ץ
جهت سنجش يايايى زرسشنامه نيز از آلفاى كرونباخ استفاده شد. در اين روش ابتدا • ع يرسشنامه تكميل گرديد و سيس آلفاى كرونباخ حيطههاى آكاهى و نكرش در اين نمونه محاسبه شد كه آلفاى كرونباخ حيطه آكاهى سنجى 191• و حيطه نكَش سنجى VY/ • محاسبه كرديد. يرسش نامههايى كه داراى بيش از • ا درصد سؤالات بىياسخ بودند، از مطالعه حذف كرديدند. قبل از تكميل يرسشنامه، از شركت كنندكان رضايت شفاهى اخذ كرديد و به افراد اطمينان داده شد كه اطلاعات محرمانه بوده و فقط جهت اهداف يزوهشى مورد استفاده قرار خواهد كرفت. دادهها پِ از جمع آورى توسط نرمافزار SPSS ن نسخه مورد تجزيه و تحليل قرار كرفت. جهت بررسى ارتباط آكاهى با نخرش، آَاهى با مصرف قليان در يك ماه اخير، نخرش با مصرف قليان در يك ماه اخير و آكاهى و نكَرش با متغيرهاى زمينهاى به ترتيب از ضريب همبستخى Pearson، آزمون مجذور كاى، آزمون t مستقل و آناليز ركرسيون خطى خند استفاده شد. سطح معنى دارى در آزمونها هـ • • در نظر كرفته

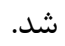
نتايج از مجموع • 11 يرسشنامه تكميل شده، · إرسشنامه به علت نواقص موجود حذف و در نهايت •9 • إيرسشنامه مورد بررسى قرار گرفت. ميانگين و انحراف معيار سن افراد

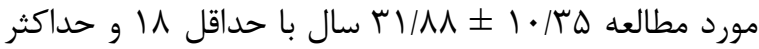

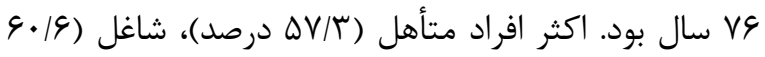


. بو آكاهى و نخرش نسبت به مصرف قليان.

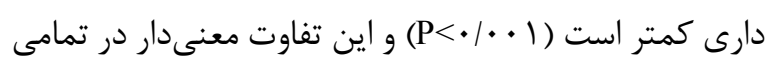

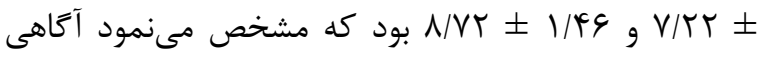

كويdهاى آكاهى سنجى مشاهده شد (جدول r).

افرادى كه در يك ماه اخير قليان مصرف كردهاند نسبت به

افرادى كه در اين مدت قليان نكشيده بودند به طور معنى

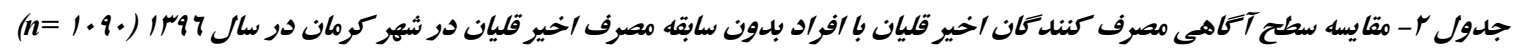

\begin{tabular}{|c|c|c|c|c|c|}
\hline \multirow[t]{3}{*}{ مقدار p } & \multicolumn{2}{|c|}{$\begin{array}{c}\text { افراد بدون سابقه مصرف قليان در } 1 \text { ماه اخير } \\
(n=V \vee \&)\end{array}$} & \multicolumn{2}{|c|}{$\begin{array}{c}\text { افراد با سابقه مصرف قليان در } 1 \text { ماه } \\
\text { اخير } \\
(\mathbf{n}=\text { MIf) }\end{array}$} & \multirow[t]{3}{*}{ كويه } \\
\hline & (درصد) تعداد ياسخ & (درصد) تعداد باسخ & (درصد) تعداد & (درصد) تعداد & \\
\hline & غلط & صحيح & ياسخ غلط & ياسخ صحيح & \\
\hline$<\cdot|\cdot \cdot|$ & $9 \Delta(N / F)$ & $111(91 / 9)$ & (1) & $r \cdot 1(\xi \varphi)$ & ا. قىشود. رشيدن باعث خوابى راحت \\
\hline$<\cdot / \cdot \cdot 1$ & $V \varepsilon(9 / \Lambda)$ & $V \cdot \cdot(q \cdot / r)$ & $\Lambda D(T V / T)$ & TYA $(Y Y / \Lambda)$ & 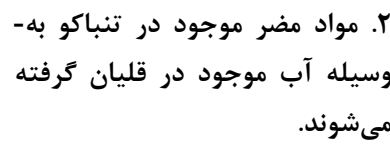 \\
\hline$\cdot / \cdot F V$ & $r \Psi \cdot(r / / 9)$ & qqV $(q \wedge / \mathcal{q})$ & $\| 11(r \wedge / F)$ & $\operatorname{IV} \wedge(9 / / 9)$ & دار. تنباكوى قليان منوكسيد كربن \\
\hline$<\cdot / \cdot \cdot 1$ & $g r(\Lambda / r)$ & $\mathrm{VI} \cdot(9) / 1)$ & $\Delta V(\mid \Lambda / T)$ & $r \Delta \varphi(\Lambda) / \Lambda)$ & 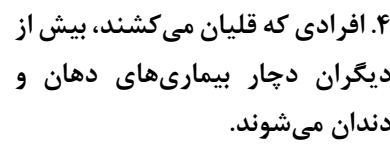 \\
\hline$<\cdot \mid \cdot \cdot 1$ & $\mid Y F(\mid 9 / 1)$ & $G \leftarrow \wedge(\Lambda \Gamma / q)$ & $q \cdot(T / / \Lambda)$ & TrT $(V \backslash / T)$ & 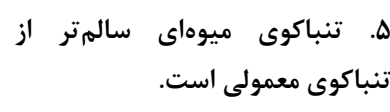 \\
\hline$<\cdot / \cdot \cdot 1$ & $\| f(\mid f / q)$ & GQT $(\Lambda \Delta / 1)$ & $11 \cdot(r \Delta / \varepsilon)$ & $199(9 F / 4)$ & هياتيت (بيمارى كبدى) ايجاد كند. عشيد. \\
\hline . I. TT & $\operatorname{rr}(\boldsymbol{\Psi} / 1)$ & $\operatorname{VFF}(9 \Delta / q)$ & $Y F(V / V)$ & r^৭ (৭r/r) & Vى شود. \\
\hline$<\cdot|\cdot \cdot|$ & $1 \Delta \Delta(T \cdot / V)$ & $\Delta Q T(\vee q / \Gamma)$ & $|f|(|\& \&| 1)$ & $19 \Delta(\Delta r / 9)$ & 1. قـ شود. ـ كشيدن باعث سرطان مثانه \\
\hline$<\cdot|\cdot \cdot|$ & $\Delta \Delta(V / r)$ & $V I \cdot(9 Y / \Lambda)$ & $\Delta \Delta(\mid N / T)$ & $\operatorname{rF\Lambda }(\Lambda) / \Lambda)$ & 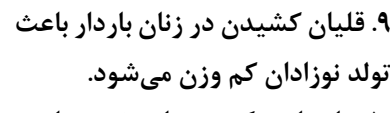 \\
\hline$<\cdot|\cdot \cdot|$ & $M(f)$ & VFT (१९) & $q q(\mid Q / \Lambda)$ & TET $(\Lambda F / T)$ & 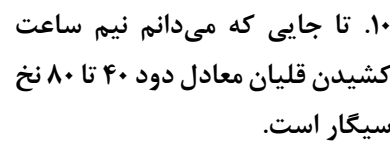 \\
\hline
\end{tabular}

آزمون مجذور كاى، 0./ > P اختلاف معنىد/ر

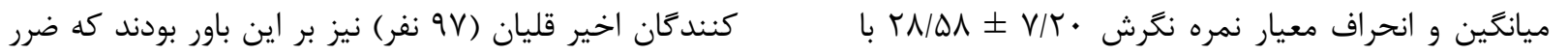

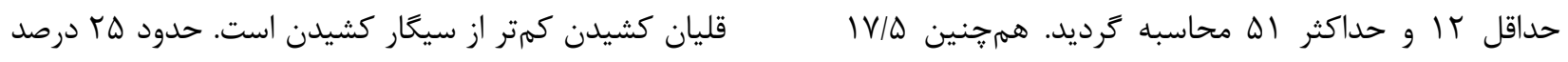

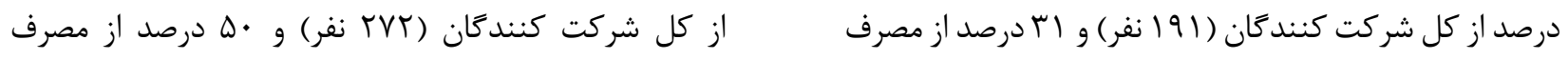


است. ميانگين و انحراف معيار نمره نخرش نيز به ترتيب در افراد با سابقه مصرف اخير قليان و افراد بدون سابقه مصرف اخير قليان V/ V مىداد نگرش افرادى كه در يك ماه اخير قليان كشيده بودند به شكل معنادارى نسبت به كسانى كه در اين مدت مصرف نداشتند مثبت در تمامى گَويههاى نخرش سنجى به جزء گويه آخر مشاهده

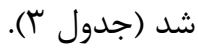

كنند تفريحى قليان اعتيادآور نيست و هس درصد از كل شركت كنند قليان (99 نفر) نيز باور داشتند كه كشيدن قليان فرصت خوبى براى وقت گذراندن با دوستان و فاميل است. همجنين حدود • V درصد از شركت كنند افراد مصرف كننده قليان (V9) اين IV در اين مطالعه اعتقاد داشتند كه قليان كشيدن در حال حاضر يك معضل اجتماعى

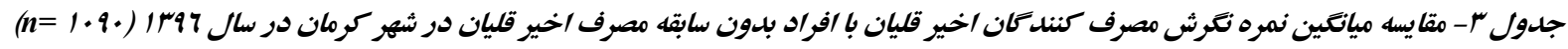

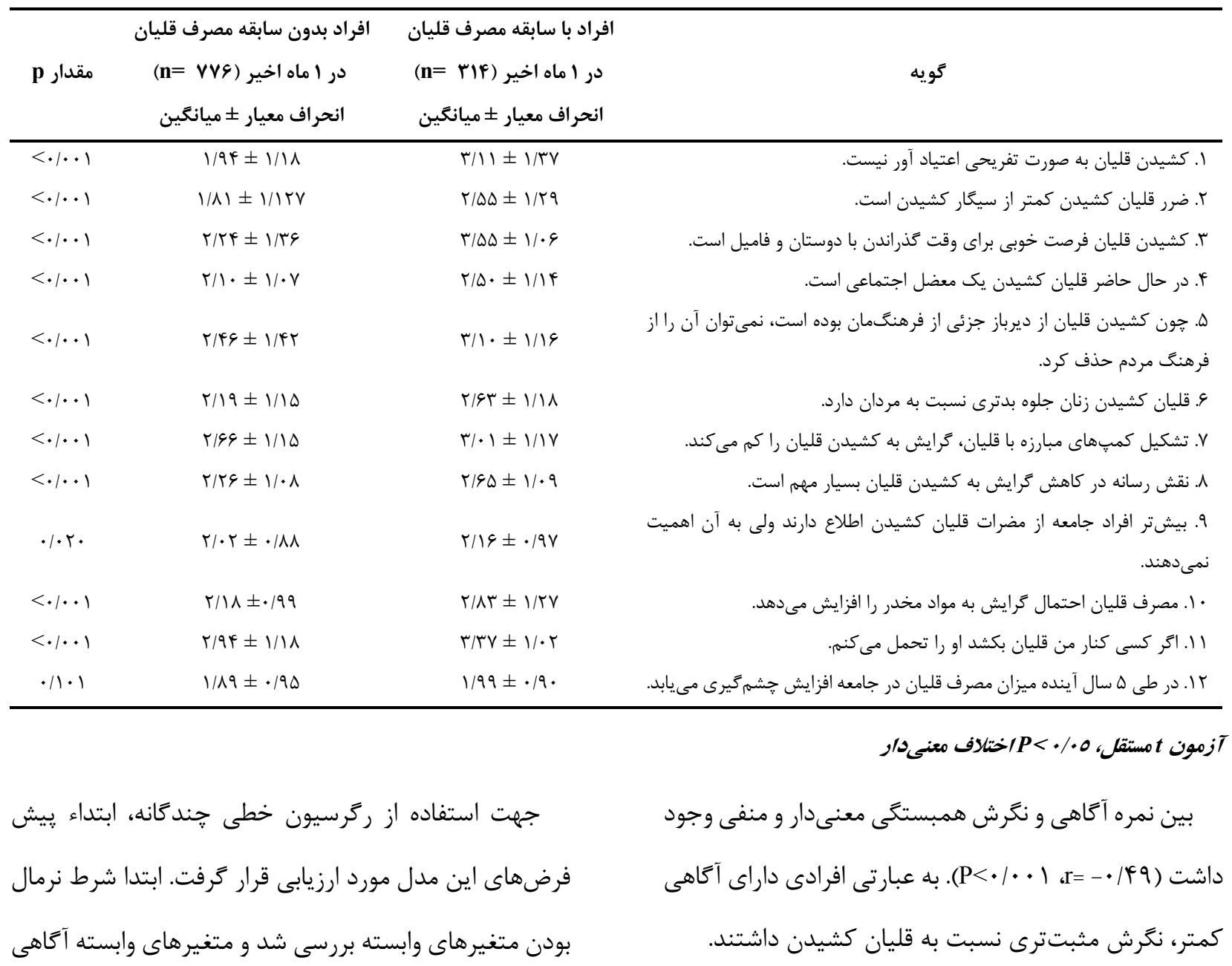


داراى سطح معنىدارى كمتر از ஈ/• بودند، وارد مدل جند

متغيره شدند.

جهت انجام آناليز رَرسيون خطى تعديل شده، تمامى متغيرهايى كه در آناليز ركرسيون خام سطح معنىدارى كمتر از ץ/· داشتند وارد مدل شدند و با استفاده از روش مورد تجزيه و تحليل قرار گرفتند. نتايج نشان داد Backward كه با يك سال افزايش سن، ميانگين نمره آگاهى به ميزان F • • • افزايش مى يابد ( ( • P<). هم جنين مردان نسبت به

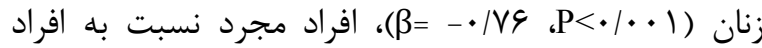

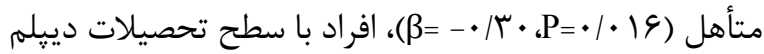

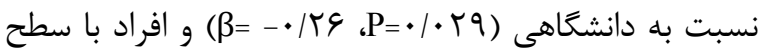

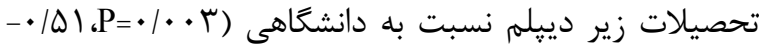

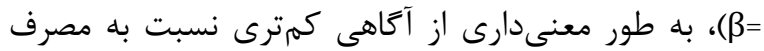
قليان برخوردار بودند. علىرغم بالاتر بودن نمره ميانكَين آكاهى در افراد خانهدار و بى كار نسبت به شاغلين و دانشجويان و همرجنين افراد با در آمد بالا نسبت به در آمد متوسط و پايين، ولى اين تفاوتها از نظر آمارى معنى دار نبود (جدول †).
و نكرش داراى نمودار هيستوگرام با توزيع متقارن بودند. سيس شرط استقلال خطاها بررسى شد و با استفاده از آزمون براى ركرسيون عوامل ييش بينى كننده Durbin-Watson آكاهى و نكرش به ترتيب اعداد • T/T و هـ/T محاسبه شد كه نشان دهنده مستقل بودن خطاها از يكديكر بود. شرط برابرى واريانس متغير وابسته در مقادير مختلف متغير مستقل، براساس نمودارهاى يراكنش بررسى شد كه بيان كننده فاصله مساوى نقاط تا خط ركرسيون براى مقادير مختلف متغيرهاى

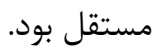

هم:جنين رابطه خطى بين متغيرهاى مستقل عددى با متغيرهاى وابسته از طريق رسم نمودارهاى يراكنش بررسى و تأييد گرديد. در نهايت پيش فرض عدم رخداد يديده همخطى بين متغيرهاى پيش بين نيز توسط آزمون عامل تورم واريانس (Variance Inflation Factor) مورد ارزيابى قرار كرفت كه تمامى مقادير اين آماره در مدل عددى بين ه/ تا r را به خود اختصاص داده بود كه نشان دهنده عدم وجود همخطى بين متغيرهاى ييشبين در اين مطالعه بود. در آناليز ركرسيون خطى جند گانه، متغيرهايى كه در مدل تك متغيره 


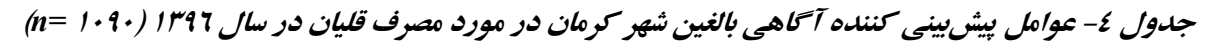

\begin{tabular}{|c|c|c|c|c|}
\hline مقدار p & 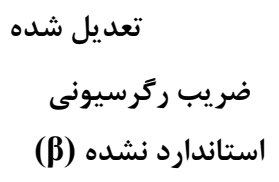 & مقدار p p & 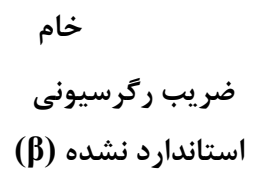 & متغير \\
\hline$<\cdot \mid \cdot \cdot 1$ & $.1 \cdot 4$ & $<\cdot \mid \cdot \cdot 1$ & .1 .4 & جنسيت (سال) \\
\hline- & - & - & 1 & زن \\
\hline$<\cdot|\cdot \cdot|$ & $-\cdot / v 9$ & $<\cdot / \cdot \cdot 1$ & $-\cdot / A r$ & وضعيت تأهل \\
\hline - & - & - & 1 & متأهل \\
\hline $.1 \cdot 19$ & $-\cdot \pi \cdot$ & $<\cdot / \cdot \cdot 1$ & -.194 & سطح تحصيلات \\
\hline - & - & - & 1 & دانشَاهى \\
\hline $.1 \cdot 49$ & $-\cdot / r V$ & $\cdot|r| \Lambda$ & -.119 & دييلم \\
\hline$\cdot \cdot \cdot r$ & $-\cdot|\Delta|$ & .111 &.$- / T \wedge$ & وضعيت اشتغال \\
\hline - & - & - & 1 & خانهدار / بى كار \\
\hline- & - & $\cdot \cdot \cdot r$ &.$- / 4 T$ & شاغل \\
\hline- & - & $<\cdot \mid \cdot \cdot 1$ & $-\cdot / 1 \Lambda$ & در آمد (ميليون ريال در ماه) \\
\hline - & - & - & 1 & بالاتر از ها \\
\hline- & - & $\cdot / 0 \cdot r$ &.$- / 1 f$ & ه تا ها \\
\hline- & - &.$/ 911$ & -.1 .1 & كمتر از هـ \\
\hline
\end{tabular}

آناليز ركوسيون خطى جندكانه، 0.• > P ارتباط معنى

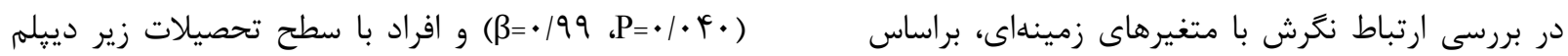

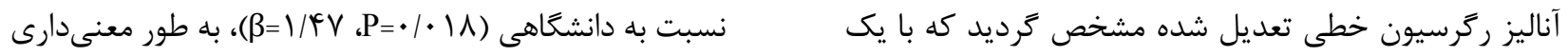
سال افزايش سن، ميانگين نمره نكرش به ميزان ه| / • كاهش از نكرش مثبتترى نسبت به مصرف قليان برخوردار بودند. در

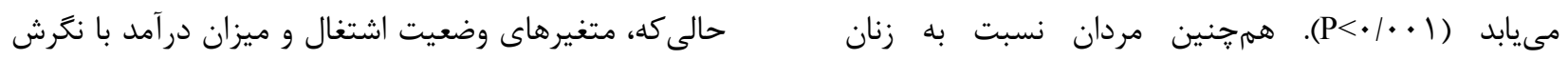

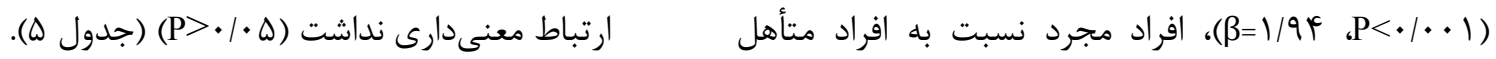


F

\begin{tabular}{|c|c|c|c|c|}
\hline مقدار p & 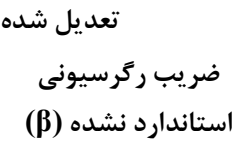 & مقدار p & 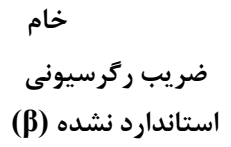 & متغير \\
\hline$<\cdot \mid \cdot .1$ & $-\cdot / 1 \Delta$ & $<\cdot|\cdot|$. & $-\cdot / 10$ & سن (سال) \\
\hline & - & - & 1 & زن \\
\hline$<\cdot \mid \cdot .1$ & $1 / 94$ & $<\cdot|\cdot|$. & $T / T \Lambda$ & وضعيت تأهل \\
\hline- & - & - & 1 & متأهل \\
\hline.$/ .4$. &.$/ 99$ & $<\cdot \mid \cdot \cdot 1$ & $r / \Gamma \Lambda$ & سطح تحصيلات \\
\hline - & - & - & 1 & دانشكاهى \\
\hline . Trar & . & - /AGT & .1 .9 & دييلم \\
\hline$\cdot 1 \cdot 11$ & $1 / \notin V$ & $\cdot|r| \Lambda$ & $\cdot 190$ & وضعيت اشتغال \\
\hline- & - & - & 1 & خانهدار / بى كار \\
\hline - & - & $\cdot 1 \cdot 1 \Delta$ & . $/ 95$ & شاغل \\
\hline- & - & $<\cdot \mid \cdot \cdot 1$ & $r / 4$. & درآمد (ميليون ريال در ماه) \\
\hline- & - & - & 1 & بالاتر از ها \\
\hline- & - & $\cdot / v \cdot r$ & $-\cdot / \mu$ & ه تا ها \\
\hline- & - &. $\mid 94 V$ & $\cdot / \pi \Delta$ & كمتر از هـ \\
\hline
\end{tabular}

آناليز ركوسيون خطى جندكانه، 0٪/•> P/رتباط معنىد/ر

درصد از مصرف كنندگان قليان بر اين باور بودند كه ضرر

قليان كشيدن كمتر از سيعار كشيدن است در حالى كه براساس يك مطالعه مرور نظامند مشخص گرديد كه در اغلب مطالعات، اكثريت پاسخ دهندكان اعتقاد داشتند كه ضرر قليان از سيكار كمتر است [4 [ ] ]. در دو مطالعه انجام گرفته در آمريكا و عربستان سعودى نيز مشخص كرديد كه به ترتيب ه/ درصد و \&q/V درصد از شركت كنندگان اعتقاد داشتند كه مصرف قليان در مقايسه با سيكار زيان كمترى دارد [4 T، 9 1]. در يك مطالعه در ايران نيز \&/• عرصد از افراد بيان نموده بودند كه قليان كشيدن يك روش سالمتر و كم خطرتر براى
ميانكين نمره آكاهى شركت كنند كان در اين مطالعه $9 /$ از حداكثر · ا بود كه نشان دهنده سطح آكاهى قابل قبول اين افراد نسبت به مصرف قليان بود. همرجنين ميانگين نمره

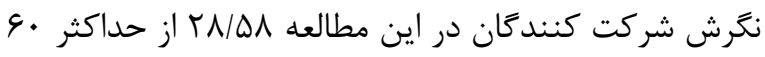
بود كه نشان دهنده نخرش منفى اين افراد نسبت به قليان كشيدن بود. مقايسه نتايج مطالعه حاضر با ساير مطالعات نشان دهنده آكاهى بيشتر و نكرش منفىتر افراد شركت كننده در اين مطالعه نسبت به مصرف قليان است. به عنوان مثال فقط

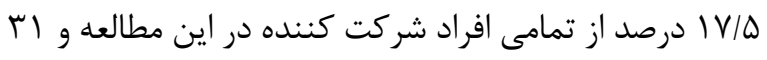


حدود • ل درصد از شركت كنندكان و \&ه درصد از افراد

مصرف كننده قليان در اين مطالعه اعتقاد داشتند كه قليان

كشيدن در حال حاضر يك معضل اجتماعى است. اين در حالى

است كه نتايج ساير مطالعات دلالت بر روند رو به افزايش

يذيرش اجتماعى مصرف قليان نسبت به مصرف سيكار به خصوص در ميان جوانان و زنان دارد و حتى برخى افراد آن را يك مد امروزى مى دانند [1·, I I , IV نتايج اين مطالعه نشان داد، مصرف كنندكان اخير قليان نسبت به افرادى كه در يك ماه كذشته مصرف نداشتند به طور معنادارى از سطح آكاهى كمتر و نگرش مثبتترى نسبت به مصرف قليان برخوردار بودند كه با يافتههاى ساير مطالعات

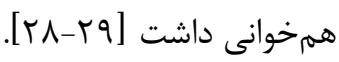

در اين مطالعه، زنان در مقايسه با مردان، به شكل معنى ارى از آكاهى بيشتر و نكَش منفىترى نسبت به مصرف قليان برخوردار بودند. نتايج اكثر مطالعات نيز حاكى از اين موضوع است كه زنان در مقايسه با مردان آكاهى بيشتر و

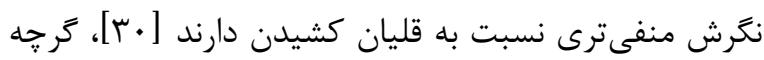
در مطالعهاى كه در هند انجام شد، آكاهى مردان نسبت به مضرات قليان نسبت به زنان بيشتر بود [اس]. با توجه به نتايج اين مطالعه، به نظر مىرسد زنان و به خصوص زنان متأهل به علت حساسيت و توجه به سلامت اعضاء خانواده از جمله فرزندان، سطح آكاهى بيشتر و نگرش منفىترى نسبت به

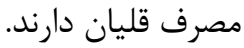
نتايج مطالعه حاضر نشان داد كه با افزايش سن، آكاهى افراد بيشتر و نكرش آنها نسبت به مصرف قليان منفىتر
مصرف تنباكو است [ب1]]. در مطالعه ديكرى كه در آمريكا انجام شد، مشخص گرديد كه س// دN درد از مصرف كنندگان قليان بر اين باورند كه ضرر مصرف قليان از سيكار كشيدن كم

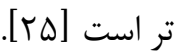
در اين مطالعه حدود فT درصد از كل شركت كنندكان و •ه درصد از مصرف كنندكان اخير قليان اعتقاد داشتند كه. مصرف تفريحى قليان اعتيادآور نيست. در حالى كه نتايج ساير مطالعات نشان مىدهد كه اكثر افراد به خصوص جوانان اعتقاد دارند كه مصرف قليان اعتيادآور نبوده يا نسبت به سيعار اعتياد آورى كمترى دارد [IV] د.] در يك مطالعه مرور نظامند مشخص كرديد كه Qr تا V9 درصد از شركت كنندكان، مصرف قليان در مقايسه با سيكار را كمتر اعتيادآور مىدانستند

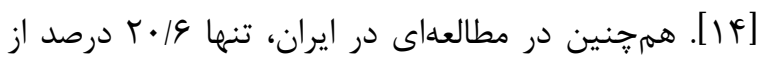
دانشجويان مصرف كننده قليان بر اين باور بودند كه قليان كشيدن اعتيادآور است [11]].

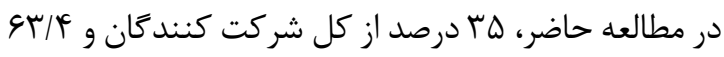
درصد از مصرف كنندگان اخير قليان باور داشتند كه كشيدن قليان فرصت خوبى براى وقت حذراندن با دوستان و فاميل است. نتايج ساير مطالعات نيز نشان مىدهد كه جنبههاى سرگرمى و اجتماعى يكى از مهمترين عوامل انخيزشى جهت مصرف قليان بوده و قليان كشيدن به افراد يك فرصت مناسب براى دور هم بودن و كذراندن وقت مى دهد [VY-צץ, سו]. يك مطالعه مشخص نمود كه / / بr درصد از افراد مورد مطالعه قليان كشيدن را فرصتى مناسب براى معاشرت با دوستان و

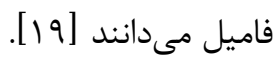




\section{نتيجهد گيرى}

يافتههاى اين مطالعه نشان داد كه مصرف كنندگان اخير

قليان، جوانان، مردان، مجردين و افراد با سطح تحصيلات

״ايين از آكاهى كمتر و نكرش مثبتترى نسبت به مصرف

قليان برخوردار بودند. بنابراين ضرورى به نظر مىرسد

سياست زاران اقدام به طراحى مداخلات مؤثر و جامعهنكرى

در راستاى افزايش آكاهى مردم از مضرات مصرف قليان و

تغيير نكرش آنها نسبت به مصرف آن به ويزه در خروههاى

در معرض خطر نمايند.

تشكر و قدردانى

نويسندًان اين مقاله مراتب تشكر و قدردانى خود را از جناب

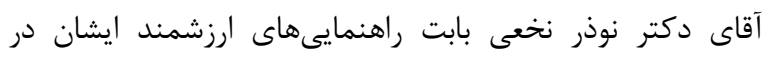

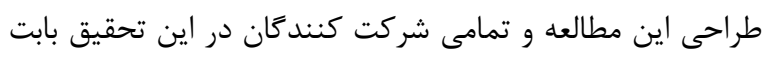

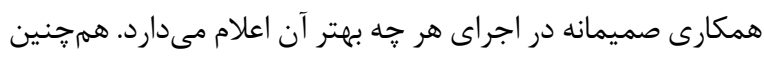

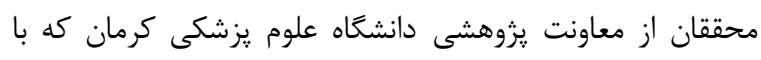

حمايت مالى خود، انجام اين تحقيق را امكان بذير نمودهاند، تشكر دران

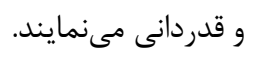

مى گردد. ساير مطالعات نيز تأييد كننده اين موضوع است كه افراد با سن بالاتر نسبت به جوانان و نوجوانان از آكاهى بيشترى نسبت به مضرات قليان كشيدن برخوردار هستند [اب[]. يكى از مهمترين دلايل اين موضوع اين است كه نوجوانان و جوانان قليان كشيدن را وسيلهاى براى سرگرمى، دور هم بودن و خوش گذرانى مىدانند.

از نقاط قوت اين مطالعه مىتوان به حجم نمونه بالا، روش

نمونه جمعيت بودن آن اشاره نمود. از محدوديتهاى مطالعه حاضر، ماهيت مقطعى آن است كه امكان بررسى ارتباط عليتى را فراهم نمى كند. يِيشنهاد مىشود كه در مطالعات آينده با استفاده از مدل اعتقاد بهداشتى، ارتباط باورهاى مردم با مصرف قليان و نيز عواملى كه باعث تغيير رفتار افراد در زمينه مصرف قليان مىشود، مورد بررسى قرار تيرد.

\section{References}

[1] Maziak W, Taleb ZB, Bahelah R, Islam F, Jaber R, Auf R, et al. The global epidemiology of waterpipe smoking. Tobacco Control 2015; 24(Suppl 1): i3-12.

[2] Maziak W. The global epidemic of waterpipe smoking. Addictive Behaviors 2011; 36(1): 1-5.
[3] Czoli CD. Bidi and hookah use among Canadian youth: findings from the 2010 Canadian Youth Smoking Survey. Prev Chronic Dis 2013; 10(1): $1-10$. 
[4] American Lung Association. Hookah smoking: A growing threat to public health. Smoke free Communities Project 2011.

[5] Bowman J. Time to smell the sweet smoke: fantasy themes and rhetorical vision in nargile cafe cultures. The Journal of Popular Culture 2009; 42(3): 442-5.

[6] Elawa F, Warren C, Jones N. Changes in tobacco use among 13-15-year-olds between 1999 and 2007: findings from the Eastern Mediterranean Region. EMHJ 2010; 16 (3): 266-273.

[7] Akl EA, Gunukula SK, Aleem S, Obeid R, Jaoude PA, Honeine $\mathrm{R}$, et al. The prevalence of waterpipe tobacco smoking among the general and specific populations: a systematic review. BMC Public Health 2011; 11(1): 1.

[8] Jawad M, Charide R, Waziry R, Darzi A, Ballout RA, Akl EA. The prevalence and trends of waterpipe tobacco smoking: A systematic review. PloS One 2018; 13(2): e0192191.

[9] Abdollahifard G, Vakili V, Danaei M, Askarian M, Romito L, Palenik CJ. Are the Predictors of
Hookah Smoking Different from Those of Cigarette Smoking? Report of a Populationbased Study in Shiraz, Iran, 2010. International Journal of Preventive Medicine 2013; 4(4): 459.

[10] Kalan ME, Taleb ZB. Waterpipe tobacco smoking: A reality or hidden iceberg for Iranian women. Health Promotion Perspectives 2018; 8(4): 252.

[11] Nemati S, Rafei A, Freedman ND, Fotouhi A, Asgary F, Zendehdel K. Cigarette and water-pipe use in Iran: Geographical distribution and time trends among the adult population; A pooled analysis of national STEPS surveys, 2006-2009. Archives of Iranian Medicine 2017; 20(5): 295.

[12] Danaei M, Jabbarinejad-Kermani A, Mohebbi E, Momeni M. Waterpipe Tobacco Smoking Prevalence and Associated Factors in the Southeast of Iran. Addiction \& Health 2017; 9(2): 72.

[13] Ghafouri N, Hirsch JD, Heydari G, Morello CM, Kuo GM, Singh RF. Waterpipe smoking among health sciences university students in Iran: 
perceptions, practices and patterns of use. $B M C$

Research Notes 2011; 4(1): 496.

[14] Akl EA, Jawad M, Lam WY, Obeid R, Irani J. Motives, beliefs and attitudes towards waterpipe tobacco smoking: a systematic review. Harm Reduction Journal 2013; 10(1): 1.

[15] Sadeghi R, Mazloomy Mahmoodabad SS, Khanjani N, Fallahzadeh H, Rezaeian M. The association between health literacy and smoking (Hookah and Cigarette) among the young men in Sirjan, Iran. Journal of Substance Use 2019; 24(5): 546-9.

[16] Primack BA, Sidani J, Agarwal AA, Shadel WG, Donny EC, Eissenberg TE. Prevalence of and associations with waterpipe tobacco smoking among US university students. Annals of Behavioral Medicine 2008; 36(1): 81-6.

[17] Momenabadi V, Kaveh MH, Hashemi SY, Borhaninejad VR. Factors Affecting Hookah Smoking Trend in the Society: A Review Article. Addiction and Health 2016; 8(2): 123.
[18] Dehdari T, Jafari A, Joveyni H. Students' perspectives in Tehran University of Medical Sciences about factors affecting smoking hookah. RJMS 2012; 19(95): 17-24.

[19] Amin TT, Amr M, Zaza BO, Suleman W. Harm perception, attitudes and predictors of waterpipe (shisha) smoking among secondary school adolescents in Al-Hassa, Saudi Arabia. Asian Pac J Cancer Prev 2010; 11(2): 293-301.

[20] Carroll MV, Shensa A, Primack BA. A comparison of cigarette-and hookah-related videos on YouTube. Tobacco Control 2013; 22(5): 319-23.

[21] Salloum RG, Nakkash RT, Myers AE, Wood KA, Ribisl KM. Point-of-sale tobacco advertising in Beirut, Lebanon following a national advertising ban. BMC Public Health 2013; 13(1): 534.

[22] Eshah NF, Froelicher ES. Knowledge, attitudes, beliefs and patterns of waterpipe use among Jordanian adults who exclusively smoke waterpipes. European Journal of Cardiovascular Nursing 2018; 17(1): 85-92. 
[23] Nakhaei N. Questionnaire design \& analysis.

Kerman, Gera publisher. 2013; 98-100.

[24] Noonan D, Patrick ME. Factors associated with perceptions of hookah addictiveness and harmfulness among young adults. Substance Abuse 2013; 34(1): 83-5.

[25] Aljarrah K, Ababneh ZQ, Al-Delaimy WK. Perceptions of hookah smoking harmfulness: predictors and characteristics among current hookah users. Tobacco Induced Diseases 2009; 5(1): 16 .

[26] Smith-Simone S, Maziak W, Ward KD, Eissenberg T. Waterpipe tobacco smoking: knowledge, attitudes, beliefs, and behavior in two US samples. Nicotine \& Tobacco Research. 2008; 10(2): 393-8.

[27] Noonan D, Kulbok PA. Beliefs and norms associated with smoking tobacco using a waterpipe among college students. Journal of Addictions Nursing 2012; 23(2): 123-8.
[28] Barnett TE, Shensa A, Kim KH, Cook RL, Nuzzo

E, Primack BA. The predictive utility of attitudes toward hookah tobacco smoking. American journalof Health Behavior 2013; 37(4): 433-9.

[29] Krenik-Matejcek TM, Monson AL, Cooper BR. Hookah Smoking: Assessing College Students' Behaviors, Attitudes, and Knowledge. Journal of Dental Hygiene 2017; 91(6).

[30] Jeihooni AK, Khiyali Z, Kashfi SM, Kashfi SH, Zakeri M, Amirkhani M. Knowledge and Attitudes of University Students Towards Hookah Smoking in Fasa, Iran. Iranian Journal of Psychiatry and Behavioral Sciences 2018; 12(1).

[31] Patle RA, Khakse GM. Study of knowledge, attitude and practices towards tobacco use in geriatric population. International Journal of Medical Science and Public Health 2014; 3(7): 859-62. 


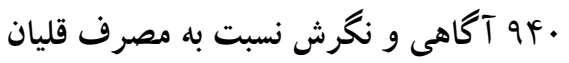

\title{
The Study of Adults' Knowledge and Attitude Towards Waterpipe Tobacco Smoking in the City of Kerman in 2017: A Descriptive Study
}

\author{
M. Danaei ${ }^{1}$ M. Momeni $^{2}$
}

Received: 10/08/2019 Sent for Revision: 29/09/2019 Received Revised Manuscript: 24/10/2020 Accepted: 31/10/2020

Background and Objectives: Today, lack of knowledge and misconceptions are the most important reasons for an increasing trend toward waterpipe tobacco smoking (WTS) worldwide. The aim of this study was to determine the knowledge and attitude of adults of city of Kerman towards WTS.

Materials and Methods: This descriptive study was performed on 1090 adults selected by multi-stage random sampling in the city of Kerman in 2017. A researcher-made questionnaire including demographic information, questions about knowledge and attitude towards WTS and a question about the current use of WTS was used. Data were analyzed using Pearson's correlation coefficient, chi-square test, independent t-test and multiple linear regression. Results: The mean and standard deviation scores of knowledge and attitude of subjects were $8.29 \pm 1.84$ and $28.58 \pm 7.20$, respectively. There was observed a significant negative correlation between knowledge and attitude score $(\mathrm{r}=-0.49 ; \mathrm{p}<0.001)$. The knowledge of current waterpipe users was significantly less than noncurrent waterpipe users $(p<0.001)$ and the attitude of current waterpipe users was significantly more positive than those noncurrent waterpipe users $(p<0.001)$. People with higher age $(p<0.001)$, women $(p<0.001)$, married $(p=0.016)$ and those with university education $(\mathrm{p}=0.003)$ had significantly more knowledge.

Conclusion: Considering the inappropriate knowledge and attitude of adults towards WTS, interventions to increase knowledge and change attitude, especially in people at risk should be designed and implemented.

Key words: Waterpipe, Knowledge, Attitude, Kerman

Funding: This study was funded by the Office of Vice-Chancellor for Research at Kerman University of Medical Sciences.

Conflict of interest: None declared.

Ethical approval: The Ethics Committee of Kerman University of Medical Sciences approved the study (IR.KMU.REC.1394.262).

How to cite this article: Danaei M, M. Momeni. The Study of Adults' Knowledge and Attitude Towards Waterpipe Tobacco Smoking in the City of Kerman in 2017: A Descriptive Study. J Rafsanjan Univ Med Sci 2020; 19 (9): 925-40 [Farsi]

1- Assistant Prof., Dept. of Community Medicine, Medical School, Neuroscience Research Center, Institute of Neuropharmacology, Kerman University of Medical Sciences, Kerman, Iran, ORCID: 0000-0002-6352-9599

2- Assistant Prof., Dept. of Community Medicine, Medical School, Social Determinants of Health Research Center, Institute for Futures Studies in Health, Kerman University of Medical Sciences, Kerman, Iran, ORCID: 0000-0002-9513-3046

(Corresponding Author) Tel: (034) 33275313, Fax: (034) 33257675, E-mail: m.momeni@kmu.ac.ir

دوره 19، شماره 9، سال 99 19

مجله دانشگاه علوم بزشكى رفسنجان 